\title{
Evaluation of the Tuberculosis Case Notification System, Mhondoro-Ngezi District, Zimbabwe, 2016
}

\section{Pamela Nyaradzai Magande ${ }^{*}$, Daniel Chirundu ${ }^{2}$, More Mungati1, Donewell Bangure ${ }^{1}$, Notion Tafara Gombe' ${ }^{1}$ Mufuta Tshimanga ${ }^{1}$}

${ }^{1}$ Department of Community Medicine, University of Zimbabwe, Harare, Zimbabwe

${ }^{2}$ Kadoma City Health Department, Kadoma City, Zimbabwe

Email: ${ }^{*}$ pmagande@gmail.com

How to cite this paper: Magande, P.N., Chirundu, D., Mungati, M., Bangure, D., Gombe, N.T. and Tshimanga, M. (2017) Evaluation of the Tuberculosis Case Notification System, Mhondoro-Ngezi District, Zimbabwe, 2016. Open Journal of Epidemiology, 7, 1-9.

https://doi.org/10.4236/ojepi.2017.71001

Received: September 10, 2016

Accepted: December 2, 2016

Published: December 5, 2016

Copyright (c) 2017 by authors and Scientific Research Publishing Inc. This work is licensed under the Creative Commons Attribution International License (CC BY 4.0).

http://creativecommons.org/licenses/by/4.0/

(c) (i) Open Access

\begin{abstract}
Background: Zimbabwe was $17^{\text {th }}$ among 22 tuberculosis (TB) high burdened countries. In Zimbabwe, the TB case notification system tracks data on case detection and treatment. Mhondoro-Ngezi district was reporting less than half provincial case average of 251 cases per 100,000 population per year. Data were always two weeks late. We evaluated the surveillance system and determined reasons for low notification. Methods: A descriptive cross sectional study was conducted using the updated CDC guidelines. Structured questionnaires, notification registers and forms were used to collect data. Epi Info 7 was used to calculate means and frequencies. Results: All 17 facilities providing $\mathrm{TB}$ services were selected. Only two of these were diagnostic centres. Of the 41 health workers, 32 (78\%) were nurses. All facilities were notifying and $38(93 \%)$ of health workers had notified cases. Notification forms were available at all facilities and were transported to the district office by government vehicles once completed. Ten minutes on average were needed to complete a form and this was easy for $89 \%$ health workers. Data were being analysed at facilities by $83 \%$ of health workers and $71 \%$ took action after analysis. Feedback from district level was being received by $85 \%$ of health workers. The reasons for low notification included: few diagnostic centres, passive case detection and poor community involvement. Conclusions: The TB case notification system was acceptable, simple, representative and useful. Reasons for low notification included: few diagnostic centres, passive case detection and poor community involvement. As a result of this evaluation, a third diagnostic centre is being set up.
\end{abstract}

\section{Keywords}

Tuberculosis, Surveillance, Mhondoro-Ngezi, Zimbabwe 


\section{Introduction}

Tuberculosis (TB), is a treatable infectious bacterial disease caused by Mycobacterium tuberculosis (MTB). It most commonly affects the lungs and is transmitted from person to person via droplets [1]. Conditions such as HIV and malnutrition can cause immunosuppression and result in symptomatic TB [2] [3].

According to the Global TB report, 2015, an estimated 9.6 million new TB infections occurred in 2014. Of these, 12\% of the cases in 2014 were HIV-positive [4]. There was a slight increase in the proportion of estimated new cases that went undiagnosed or were not reported from 36\% in 2013 to 37\% in 2014 worldwide [4] [5]. Although the number of new cases is high, globally, the treatment success rate for people newly diagnosed with TB has been above $80 \%$ since 2005 [5]. As a result global TB prevalence rate has fallen by $41 \%$ and TB mortality rate has fallen worldwide by an estimated 47\% since 1990 [4] [5].

In 2000, the Millennium Development Goals (MDGs) were set. The sixth MDG was to combat HIV/AIDS, malaria and other diseases such as TB. One of the targets for this MDG was to halt and reverse TB incidence [6]. This target was been achieved in 16 of the 22 high-burden countries such as Zimbabwe [4]. The estimated prevalence of TB in Zimbabwe fell from 409 per 100,000 in 2013 to 292 per 100,000 in 2014 . TB mortality fell from 40 per 100,000 to 15 per 100,000 in the same period [4] [5].

To be able track progress made in TB control and see if set targets such as the MDGs, have been met, a functional surveillance system is important. In Zimbabwe, the TB case notification system is part of routine disease surveillance. Data on case detection and treatment outcomes are reported. Figure 1 summarizes flow of data [7].

Mhondoro-Ngezi District is one of the seven districts in Mashonaland West Province, Zimbabwe. Mhondoro-Ngezi district consistently reported less than half the provincial average of 251 cases per 100,000 population per year. The district TB statistics were consistently reaching the provincial two weeks late compared to other districts. The reasons for the low notification rate were not known. We evaluated the system and determined the reasons for the low notification rate.

\section{Methods}

A descriptive cross sectional study was conducted in Mhondoro-Ngezi in April 2016 using the updated Centers for Disease Control and Prevention (CDC) guidelines for surveillance system evaluation [8]. The primary respondents were health workers.

\subsection{Sample Size Calculation}

Using $92 \%$ of health workers who had knowledge on TB from a study by Chadambuka et al. (2011) at 95\% confidence interval and Dobson formula, given that the district has 133 health workers, a minimum sample size of 61 health workers was calculated. Using $83 \%$ of forms which were complete from the same 


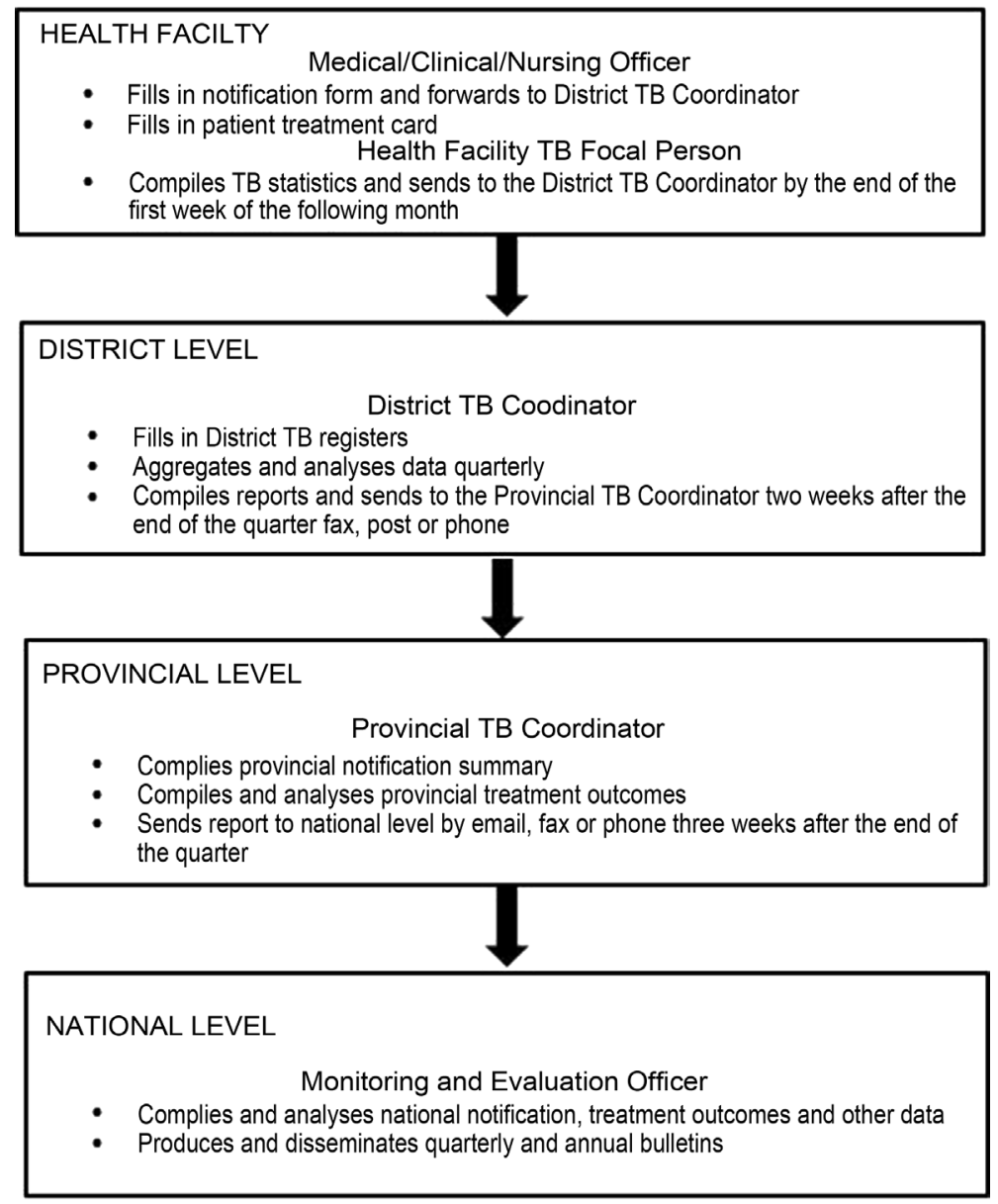

Figure 1. Flow of TB case notification data in Zimbabwe.

study, at 95\% confidence interval and using Dobson formula, a minimum sample of 54 forms was calculated [9].

\subsection{Data Collection and Analysis}

Structured questionnaires were administered to health workers to collect data on reasons for low notification and system attributes such as acceptability, stability, data quality, completeness and representativeness. The questionnaires were made from adapting the updated CDC guidelines [9]. Pre-testing of the questionnaire was done in Kadoma City. Records reviews were used to objectively assess the same.

To assess data quality, the notification forms completed between 2013 and 2015 were randomly selected and examined to see if there were missing variables. The fields with the missing variables were then expressed as a percentage of the total number of fields.

Acceptability was assessed using the following criteria; whether health facilities were notifying cases, history of ever notifying a case by the health workers, their willingness to continue participating and have the system to remain in place. The system was said to be acceptable if three or all of these indicators were met.

To assess stability, the health workers were interviewed on the following; 
whether they had received formal training on TB case notification, previous TB case notification form stock outs, current notification form availability, methods used to transfer forms to the district office and the adequacy of time for filling in the form. The system was said to be stable if three or all of these indicators were met.

Simplicity was subjectively assessed through use of the following indicators; time taken to complete one form, whether difficulties faced during the process, if there was need for specialised training, ease of access to the information required on the form, number of organisations involved in receiving the form and the method used to transfer information to the next level. The system was said to be stable if three or all of these indicators were met.

To assess representativeness, the percentage of facilities reporting cases, number of diagnostic centres, whether community TB cases and deaths were being reported. This was done as a description to have a picture of the distribution of the services (and by proxy the surveillance system) by place.

Whether the information collected was being analysed at source resulting in some kind of action being taken, whether there was any feedback from the next level and resultant action were the indicators to be met before the system could be said to be useful.

Data were captured from the questionnaires and analyzed using Epi Info $7^{\text {tix }}$ (CDC, 2012). Frequencies and means were calculated using this software. Permission was obtained from the local health authorities and the MPH Health Studies Office. Voluntary written informed consent was obtained from all participants before the interviews. Confidentiality was assured and maintained throughout the study.

\section{Results}

Although the calculated sample size was 61,41 health workers were recruited into the study. All the 17 health centres which are under the Ministry of Health and Child Care and providing TB services were included in the study. Seventy-eight percent of the health workers were nurses, environmental health technicians and laboratory scientists accounted for $5 \%$ each and $2 \%$ were microscopists. The median age was 35 years $\left(\mathrm{Q}_{1}=31, \mathrm{Q}_{3}=42\right)$. The median time in post was $9\left(Q_{1}=7, Q_{3}=13\right)$. The demographic characteristics of the participants are summarised in Table 1.

\subsection{System Attributes}

\subsubsection{Data Quality}

Sixty notification forms was reviewed for data quality. Eight percent of the notification forms were $<99 \%$ complete, the rest were $100 \%$ complete. On one form, both the TB number and address were missing. On four of the forms the addresses of client was missing. The handwriting on forms was legible.

\subsubsection{Acceptability}

All the participants, (41) reported that, their health facilities notified TB cases, 
Table 1. Demographic characteristics of the health workers in Mhondoro-Ngezi district, 2016.

\begin{tabular}{|c|c|c|}
\hline Variable & Category & n (\%) \\
\hline \multirow[t]{5}{*}{ Designation } & Junior nurse & $18(44)$ \\
\hline & Senior nurse & $14(34)$ \\
\hline & Sister in charge & $4(10)$ \\
\hline & Other & $3(7)$ \\
\hline & Environmental Health Technician & $2(5)$ \\
\hline \multirow[t]{6}{*}{ Professional qualifications } & Primary Care Nurse & $18(44)$ \\
\hline & Registered General Nurse & $13(22)$ \\
\hline & Midwife & $5(12)$ \\
\hline & Environmental Health Technician & $2(5)$ \\
\hline & Laboratory Scientist & $2(5)$ \\
\hline & Microscopist & $1(2)$ \\
\hline \multirow[t]{2}{*}{ Sex } & Female & $22(54)$ \\
\hline & Male & $19(46)$ \\
\hline \multicolumn{2}{|c|}{ Median age in years $\left(\mathrm{Q}_{1}, \mathrm{Q}_{3}\right)$} & $35\left(\mathrm{Q}_{1}=31, \mathrm{Q}_{3}=42\right)$ \\
\hline \multicolumn{2}{|c|}{ Median time in service in years $\left(Q_{1}, Q_{3}\right)$} & $9\left(Q_{1}=7, Q_{3}=13\right)$ \\
\hline
\end{tabular}

they were willing to continue participating and the system should remain in place. However, $7 \%$ had never notified a TB case. The acceptability attributes are presented in Table 2.

\subsubsection{Stability}

Seventy-six percent of health workers had received on-job training TB notification and $24 \%$ had not. Stock-outs of notification forms were reported by $12 \%$ of health workers. At the time of the study, all facilities had notification forms in stock. To send completed forms to the district office, government vehicles (98\%) and private transport (2\%) were used. Time was adequate for health workers to complete the forms (88\%). Stability attributes are presented in Table 3.

\subsubsection{Simplicity}

Sixty-eight percent of health workers had filled in notification forms. The time taken to complete the form was $<10$ minutes for $75 \%$ and 11 minutes or more for $25 \%$. Difficulties in filling in the form were faced by $11 \%$ of the health workers. The need for specialised training was cited by $66 \%$ of health workers. Eighty-four percent of health workers reported that information required to fill in forms was easy to get. All health workers (100\%) noted that there was only one organisation involved in receiving of reports and this was identified as Ministry of Health and Child Care.

\subsubsection{Representativeness}

The representativeness of the system with regards to reporting sites and ability to pick up community cases was assessed. All (17) facilities were reporting TB cases. There were two diagnostic centres in the district but all facilities receive their sputum investigation results from these centres either through phone calls 
Table 2. Acceptability of the TB case notification system, Mhondoro-Ngezi district, 2016.

\begin{tabular}{ccc}
\hline Variable & Category & n (\%) \\
\hline Health facility notifies cases & Yes & $41(100)$ \\
Ever notified TB case & No & $0(0)$ \\
Continued participation & Yes & $38(93)$ \\
& No & $3(7)$ \\
System to remain in place & Yes & $41(100)$ \\
& No & $0(0)$ \\
& Yes & $41(100)$ \\
& No & $0(0.0)$ \\
\hline
\end{tabular}

Table 3. Stability of the TB case notification system, Mhondoro-Ngezi district, 2016.

\begin{tabular}{ccc}
\hline Variable & Category & $\mathbf{n}(\%)$ \\
\hline Trained on TB case notification & Yes & $31(76)$ \\
& No & $10(24)$ \\
Notification form stock-outs & Yes & $5(12)$ \\
& No & $28(68)$ \\
Notification form availability & Don't know & $8(20)$ \\
& Yes & $41(100)$ \\
Sending forms & No & $0(0)$ \\
& Government vehicle & $40(98)$ \\
Is time available/adequate & Private transport & $1(2)$ \\
& Yes & $36(88)$ \\
& No & $5(12)$ \\
\hline
\end{tabular}

or government vehicle transportation. The two diagnostic centres are on opposite boundaries of the district and are approximately 190 kilometres apart. Community $\mathrm{TB}$ cases were being reported in $73 \%$ of cases and community $\mathrm{TB}$ deaths in $99 \%$ of cases.

\subsection{Usefulness}

Eighty-three percent of health workers analysed data at their sites. Action was taken after analysis by $71 \%$ of the health workers. Action taken was contact tracing (71\%), health education (17\%) and intensified case finding (12\%). The TB notification information was used for assessment of control programs (36\%), detection of changes in trend (39\%) and quantifying the disease burden (25\%). The information was shared with stakeholders by $74 \%$ of the health workers and the minutes of the meetings were available. However there was no involvement of community stakeholders. Of the $85 \%$ who had received feedback from the District Health Executive after reporting, 89\% reported using the feedback reports.

\subsection{Reasons for Low TB Case Notification Rate}

The reason given for the low notification rate by the health workers was that 
there were two diagnostic centres in the district (98\%) and passive case finding (73\%).

From key informants, community low awareness and involvement, passive case finding (4/5) and competing programs priority being given to programs that are well funded (1/5) were reasons for low TB case notification.

\section{Discussion}

The data quality was good on the notification forms. This can be explained by the fact that most health workers have been in service for a long time and have participated in the system for a long time. As a result the health workers have become competent. This is consistent with the results of an evaluation done by the CDC in the United States of America in 2006 when they reported completeness of case reports [10]. It is also consistent with Lo et al. (2011) who also reported completeness of notification forms in Taiwan [11].

In this study, the participants were notifying cases, willing to continue participating and wanted the system to remain in place. It is possible that the health workers in Mhondoro-Ngezi district have an understanding on the importance and impact of having a functional TB case notification system and therefore are willing to continue participating. The results in this study are consistent with Asif et al. (2015) who reported that in Hyderabad, Pakistan, the health workers were motivated to provide accurate, consistent and complete information and suggested good acceptability of the TB notification system [12]. It is however not consistent with an evaluation done by Saeed et al. (2013) who found that the TB notification system was not acceptable in Afghanistan [13].

On-job training was adequate for the health workers to notify cases, the forms were available and government vehicles were being used to transport the forms. This points towards a stable surveillance system. This is consistent with Asif et al. (2015) and Saeed et al. (2013) who also reported having evaluated stable TB notification systems [12] [13]. This could be an indicator of a program maturity.

The TB notification information was being analysed and used at the points of generation. This points towards the usefulness of the system. The TB notification information was considered useful for the purpose of assessment of control programs, detection of changes in trend and quantifying the disease burden. This allows the health workers to plan and budget for activities well. These results are consistent with Asif et al. (2015) who also found the TB notification system to be useful [12]. They are however not consistent with Velayutham et al. (2015) who found that the TB notification system was not useful in India. The differences in the findings can be explained by the fact that Velayutham et al. (2015) conducted their study among private practitioners whereas in this study, the study population were health workers in public institutions [14].

The use of TB notification information in Mhondoro-Ngezi is consistent with a report by Sockett (1995). According to Sockett (1995), use of surveillance data should include the identification and control of disease outbreaks; the development, implementation and monitoring control activities, the production of sta- 
tistics to resource allocation; and contributions to international surveillance activities [15].

There was no involvement of other community stakeholders such as community leaders and faith based organisations during the sharing of information. Community stakeholders have influence and can assist in improving public health programs. Their involvement was encouraged.

The calculated sample size of 61 could not be reached because of competing programs. This may have reduced the power of our study.

\section{Conclusion}

This study sought to evaluate the TB notification system in Mhondoro-Ngezi. Data were of good quality and complete. The TB notification system was acceptable, stable, simple, representative and useful. The reasons for the low notification rate included having only two diagnostic centres in the district, low awareness and involvement in the community regarding $\mathrm{TB}$, passive case detection and underfunding of the program. As a result of this evaluation, a third diagnostic centre is being set up.

\section{Acknowledgements}

We are grateful to Kadoma City Council for their support during the study. We are also grateful to the health workers in Mhondoro-Ngezi for their day to day hard work and their cooperation during the conduct of this study. To the CDC and the Zimbabwe FETP program, thank you for financial and technical assistance.

\section{References}

[1] World Health Organization (2016) Health Topics, Tuberculosis (TB). http://www.who.int/topics/tuberculosis/en/

[2] Mayo Clinic (2016) Patient Care \& Health Information Diseases \& Conditions, Tuberculosis.

http://www.mayoclinic.org/diseases-conditions/tuberculosis/home/ovc-20188556

[3] McIntosh, J. and Webberley, H. (2016) Tuberculosis: Treatments and Prevention. http://www.medicalnewstoday.com/articles/8856.php

[4] World Health Organization (2016) Global Tuberculosis Report 2015. http://www.who.int/tb/publications/global_report/en/

[5] World Health Organization, (2016) Global Tuberculosis Report 2014. http://www.who.int/tb/publications/global_report/archive/en/

[6] World Health Organisation (2016) Millenium Development Goals. http://www.who.int/topics/millennium_development_goals/diseases/en/

[7] Ministry of Health and Child Care (2010) Zimbabwe National Tuberculosis Control Programme, National TB Guidelines, 4th Edition.

[8] Centres for Disease Control and Prevention (2001) Updated Guidelines for Evaluating Public Health Surveillance Systems, Recommendations from the Guidelines Working Group. MMWR Recommendations and Reports, 50, 1-35. http://www.cdc.gov/mmwr/preview/mmwrhtml/rr5013a1.htm 
[9] Chadambuka, A., Mabaera, B., Tshimanga, M., Shambira, G., Gombe, N.T. and Chimusoro, A. (2011) Low Tuberculosis Case Detection in Gokwe North and South, Zimbabwe in 2006. African Health Sciences, 11, 190-196.

[10] Sprinson, J.E., Lawton, E.S., Porco, T.C., Flood, J.M. and Westenhouse, J.L. (2006) Assessing the Validity of Tuberculosis Surveillance Data in California. BMC Public Health, 6, 217. https://doi.org/10.1186/1471-2458-6-217

[11] Lo, H., Yang, S., Chou, P., Chuang, J. and Chiang, C. (2011) Completeness and Timeliness of Tuberculosis Notification in Taiwan. BMC Public Health, 11, 915. https://doi.org/10.1186/1471-2458-11-915

[12] Asif, M., Baig, M.A. and Shah, M.N. (2015) Evaluation of the Tuberculosis Surveillance System in District Hyderabad, Province Sindh-Pakistan, 2012. International Journal of Tropical Disease \& Health, 9, 1-8. https://doi.org/10.9734/IJTDH/2015/17492

[13] Saeed, K.M., Bano, R. and Asghar, R.J. (2014) Evaluation of the National Tuberculosis Surveillance System in Afghanistan. PLoS ONE, 9, e93858.

[14] Velayutham, B., Thomas, B., Nair, D., Thiruvengadam, K., Prashant, S., Kittusami, S., et al. (2015) The Usefulness and Feasibility of Mobile Interface in Tuberculosis Notification (MITUN) Voice Based System for Notification of Tuberculosis by Private Medical Practitioners-A Pilot Project. PLoS ONE, 10, e0138274. https://doi.org/10.1371/journal.pone.0138274

[15] Sockett, P.N. (1995) Communicable Disease Surveillance: Strengthening the National Perspective. Canadian Journal of Infectious Diseases, 6, 165-168. https://doi.org/10.1155/1995/478130

Submit or recommend next manuscript to SCIRP and we will provide best service for you:

Accepting pre-submission inquiries through Email, Facebook, LinkedIn, Twitter, etc. A wide selection of journals (inclusive of 9 subjects, more than 200 journals) Providing 24-hour high-quality service User-friendly online submission system Fair and swift peer-review system Efficient typesetting and proofreading procedure Display of the result of downloads and visits, as well as the number of cited articles Maximum dissemination of your research work

Submit your manuscript at: http://papersubmission.scirp.org/ Or contact ojepi@scirp.org 